\title{
Pregnancy Outcomes in Subjects Exposed to Certolizumab Pegol
}

\author{
Megan E.B. Clowse, Douglas C. Wolf, Frauke Förger, John J. Cush, Amanda Golembesky, \\ Laura Shaughnessy, Dirk De Cuyper, and Uma Mahadevan
}

\begin{abstract}
Objective. To provide information on pregnancy outcomes in women receiving certolizumab pegol (CZP).

Methods. The UCB Pharma safety database was searched for pregnancies through to September 1, 2014. Reports for maternal and paternal CZP exposure were included and outcomes examined, and data on CZP exposure, pregnancy, comorbidities, and infant events were extracted by 2 independent reviewers. Concomitant medications and disease activity were reviewed for clinical trial patients.

Results. Of 625 reported pregnancies, 372 (59.5\%) had known outcomes. Paternal exposure pregnancies $(\mathrm{n}=33)$ reported 27 live births, 4 miscarriages, 1 induced abortion, and 1 stillbirth. Maternal exposure pregnancies $(n=339)$ reported 254 live births, 52 miscarriages, 32 induced abortions, and 1 stillbirth. Almost all reported pregnancies had exposure to CZP in the first trimester, when organogenesis takes place, and a third of them continued the drug into the second and/or third trimesters. The most frequent indications for maternal CZP use were Crohn disease (192/339) and rheumatic diseases (118/339). Twelve cases of congenital malformation and a single neonatal death were reported.

Conclusion. Analysis of pregnancy outcomes after exposure to CZP supports previous reports, suggesting a lack of harmful effect of maternal CZP exposure on pregnancy outcomes. However, additional data from a larger number of outcomes after exposure and studies including an unexposed comparison group are required to fully evaluate CZP safety and tolerability in pregnancy. (First Release November 1 2015; J Rheumatol 2015;42:2270-8; doi:10.3899/jrheum.140189)
\end{abstract}

Key Indexing Terms:

CERTOLIZUMAB PEGOL PREGNANCY MISCARRIAGE CONGENITAL MALFORMATIONS

From Duke University Medical Center, Durham; Union Chimique Belge (UCB) Pharma, Raleigh, North Carolina; Atlanta Gastroenterology Associates, Atlanta, Georgia; Baylor Research Institute and Baylor University Medical Center, Dallas, Texas; University of California San Francisco (UCSF) Center for Colitis and Crohn's Disease, San Francisco, California, USA; Department of Rheumatology, Immunology and Allergology, Inselspital, University of Bern, Bern, Switzerland; UCB Pharma, Brussels, Belgium.

Study and publication supported by UCB Pharma. UCB Pharma sponsored the study and the development of the manuscript, and approved the manuscript. Dr. Clowse has received consulting fees from UCB Pharma. Dr. Wolf has received consulting fees, research grants, and speaker fees from UCB Pharma. Dr. Förger has received consultant and speaker fees from UCB Pharma. Dr. Cush has received research grants from UCB Pharma. Drs. Golembesky, Shaughnessy, and De Cuyper are employees of UCB Pharma. Dr. Mahadevan has received consultant fees from UCB Pharma.

M.E. Clowse, MD, Duke University Medical Center; D.C. Wolf, MD, Atlanta Gastroenterology Associates; F. Förger, MD, Department of Rheumatology and Immunology and Allergology, Inselspital, University of Bern; J.J. Cush, MD, Baylor Research Institute and Baylor University Medical Center; A. Golembesky, PhD, UCB Pharma; L. Shaughnessy, PhD, UCB Pharma; D. De Cuyper, MD, UCB Pharma; U. Mahadevan, $M D, U C S F$ Center for Colitis and Crohn's Disease.

Address correspondence to Dr. M. Clowse, Duke University Medical Center 3535, Durham, North Carolina 27710, USA.

E-mail:megan.clowse@duke.edu

Full Release Article. For details see Reprints/Permissions at jrheum.org Accepted for publication August 13, 2015.
Inflammatory diseases, including rheumatoid arthritis (RA) and Crohn disease (CD), often affect women of reproductive age. Evidence suggests that the risk of adverse pregnancy outcomes is correlated with maternal disease activity and that active disease complicates pregnancy outcomes ${ }^{1,2,3,4}$. Discontinuation of medication because of pregnancy has also been associated with delivery at an earlier gestational age ${ }^{5}$. Therefore, to achieve the best fetal and maternal outcomes, there is a need for optimum maternal health and adequate disease control during pregnancy.

Antitumor necrosis factor (anti-TNF) medications are often used for the treatment of inflammatory diseases; however, only a few immunosuppressive drugs are considered safe during pregnancy by regulatory authorities ${ }^{6}$. Several updated reviews, including a systematic literature review, have investigated the safety of anti-TNF therapy use during pregnancy and breastfeeding ${ }^{7,8,9}$. These reports suggest that anti-TNF can be useful for controlling disease activity during pregnancy with no obvious effect on pregnancy outcomes to date, although treatment decisions need to be made on a case-by-case basis to evaluate potential toxic effects against the harm of high maternal disease activity on pregnancy outcomes. They also acknowledge that

Personal non-commercial use only. The Journal of Rheumatology Copyright $($ C 2015. All rights reserved. 
data regarding the effect of such therapies on pregnancy outcomes are currently limited, and thus safety during pregnancy cannot be adequately assessed. Based on the available data, guidelines from expert physicians advise continuation of anti-TNF therapy in CD during pregnancy at least through the second trimester when justified by maternal disease activity ${ }^{10,11}$. In RA, anti-TNF can be continued during pregnancy if warranted by maternal disease ${ }^{12}$. It is recommended that anti-TNF therapy be discontinued during the third trimester to limit fetal transfer of these drugs close to term.

Certolizumab pegol (CZP) is a PEGylated Fc-free anti-TNF therapy approved in over 50 countries for the treatment of RA, ankylosing spondylitis, axial spondyloarthritis, psoriatic arthritis, and $\mathrm{CD}^{13}$. CZP differs from other anti-TNF because it lacks an antibody Fc-region, which is known to play a key role in active materno-fetal placental transfer by binding to the neonatal $\mathrm{Fc}$ receptor $(\mathrm{FcRn})^{14}$. Because of the absence of an Fc-region, CZP does not bind human FcRn and consequently does not undergo FcRn-mediated transfer across the placenta ${ }^{15}$. Lack of FcRn binding may also explain the absence of placental transfer in an in vivo rodent model, an ex vivo human placental transfer model, and in an observational clinical study $16,17,18$. However, clinical data are limited, and the US Food and Drug Administration (FDA) prescribing information indicates that CZP should be used during pregnancy only if clearly needed $^{19}$, while the European Medicines Agency's Summary of Product Characteristics states that CZP is not recommended during pregnancy ${ }^{20}$.

The objective of our investigation was to provide information on the pregnancy outcomes of women and infants exposed to CZP in a retrospective analysis of pregnancy case reports in the Union Chimique Belge (UCB) Pharma safety database up to September 1, 2014. Data were also collected on pregnancies where a male partner reported exposure around the time of conception. Our study reports pregnancy outcomes and maternal demographics, including information on trimesters of CZP exposure, maternal disease activity, and concomitant medication usage, for the largest count of CZP-exposed pregnancies to date.

\section{MATERIALS AND METHODS}

The UCB Pharma drug safety database was searched for all CZP-exposed pregnancy reports. Pregnancy data were obtained from several sources, such as spontaneous reports, where information was received directly from healthcare professionals (e.g., physicians, pharmacists, and nurses) or consumers (e.g., patients, family members, and lawyers) as well as interventional and noninterventional studies (NIS). Reports from the literature were not included because it was not possible to validate the data from those sources.

FDA guidelines for evaluating the risks of drug exposure in human pregnancies were followed ${ }^{21}$. When notification of a pregnancy report was received, it triggered targeted followup with the reporter using a specialized pregnancy reporting form. Among other covariates, information sought from the reporter included first date of last menstrual period and estimated date of delivery; details of exposure to CZP and concomitant drugs within 3 months prior to conception and during pregnancy; results of prenatal investigations; maternal characteristics including age, weight, and comorbid diseases; and the woman's obstetric history. Information on the course of the pregnancy (including adverse events experienced by the mother) was also requested. In paternal exposure pregnancies, information on exposure date, maternal medical history, and maternal concomitant medications was sought.

Outcomes were considered for pregnancies after paternal (father received $\mathrm{CZP}$ ) and maternal exposures (mother received CZP). Data were collected from both prospective and retrospective reports; a prospective pregnancy was defined as a pregnancy for which there was no prenatal diagnosis of a fetus with a congenital defect and the pregnancy was still ongoing at the time of the initial report to UCB Pharma. A retrospective pregnancy constituted either a pregnancy with a prenatal diagnosis of a congenital defect or a pregnancy that had already been completed at the time of the report. Pregnancies were reported from the start of CZP clinical development (earliest report dated July 12, 2001) and continued postmarketing. For our manuscript, the cutoff date for data collection from the safety database was September 1, 2014. Data on exposure, pregnancy dating, maternal comorbidities, and infant events were extracted from case reports by 2 independent reviewers; reconciliation for discrepancies was performed by a third independent reviewer when necessary.

Pregnancy dating was based on available information in a hierarchy of data, according to reliability; gestational age at pregnancy outcome and the pregnancy outcome date (if reported) were used first. If these dates were not available, the estimated date of delivery was used and/or the last menstrual period date was used as a final option to date the pregnancy. Trimesters of pregnancy were determined using the above algorithm and distinguished as first trimester up to 12 weeks and 6 days, second trimester from 13 weeks to 28 weeks and 6 days, and third trimester as any time including and after 29 weeks ${ }^{22}$. Earliest trimester of exposure was determined by using the start and stop dates of exposure to the drug as reported in the case narrative and corresponding to the dates of the pregnancy as calculated from the hierarchy of pregnancy dates described above. For cases where these dates were incomplete or unclear, a separate review by 2 independent reviewers was conducted to determine when exposure occurred.

Pregnancy outcome was categorized and defined as follows: live birth, miscarriage (noninduced embryonic or fetal death or passage of products of conception before 20 weeks of gestation), induced abortion (medically indicated or elective), and stillbirth (a fetal death occurring at $\geq 20$ weeks of gestation). Outcomes were followed up with the case reporter (predominantly the treating physician), including both written and telephone contact attempts, starting within 30 days of estimated delivery date (EDD) and continuing over several months. When an EDD was not available, it was automatically calculated as 9 months after the date of the pregnancy report. If no information on pregnancy outcome was available by the cutoff date, the pregnancy outcome was considered unknown. Ongoing pregnancies included any pregnancy with an estimated (or calculated) due date after August 31, 2014. All other reports with an unknown outcome were considered lost to followup.

Disease activity information was retrieved for patients within clinical trials until the trial exit because of pregnancy. Data presented here are from a previous 2013 data cut, not updated because of a limited number of new cases. Because data originated from a variety of clinical trials, disease activity was reported with multiple clinical measures. The clinical measures used for the majority of subjects were the Crohn's Disease Activity Index (CDAI) for CD and the Disease Activity Score in 28 joints (DAS28) with erythrocyte sedimentation rate (ESR) for RA. Disease activity was obtained at trial baseline (study entry) and the visit prior to the pregnancy report, and was stratified by pregnancy outcome.

Concomitant medications were identified as those taken between the most recent visit prior to pregnancy report and pregnancy report date (excluding those that ended before start of pregnancy report visit and those that started after pregnancy report date). Concomitant medication start date

Personal non-commercial use only. The Journal of Rheumatology Copyright @ 2015. All rights reserved. 
was available for most patients in clinical trials; however, because patients were withdrawn from the clinical trial at the point where pregnancy was reported, the information available for concomitant medication end dates may be unreliable or sometimes absent. Summarized concomitant medication analysis was thus restricted to patients for whom the concomitant medication end date was available. Missing data were imputed.

\section{RESULTS}

At the September 1, 2014 cutoff date, 625 pregnancies were reported, of which 579 (92.6\%) and $46(7.4 \%)$ occurred following maternal and paternal CZP exposures, respectively (Figure 1).

Overview of all reported maternal pregnancy reports. Among the 579 maternal pregnancy reports, outcomes were available for 339 pregnancies with the majority of the pregnancies with unknown outcome being considered lost to followup (176/240, 73.3\%; Figure 1). Pregnancies with unknown outcomes were more likely to be spontaneous reports $(87.5 \%$ vs $64.0 \%$, respectively) and prospective $(97.5 \%$ vs $66.7 \%$, respectively) compared with pregnancies with available outcomes. There were no differences by country or indication (data not shown).

Of the 339 maternal exposure pregnancies with known outcomes, $226(66.7 \%)$ and $113(33.3 \%)$ arose from prospective and retrospective reports, respectively (Figure 1). The majority of pregnancies occurred in North America $(72.0 \%)$ and Europe $(22.1 \%)$. Report sources were spontaneous $(64.0 \%)$, clinical trials $(9.1 \%)$, and other studies (26.8\%), which included NIS, healthy volunteer studies, open-label extensions, and compassionate use. The majority of pregnancies were in women with $\mathrm{CD}$. Overall, 254 (74.9\%) live birth pregnancies, 52 (15.3\%) miscarriages, 32
(9.4\%) induced abortions, and 1 stillbirth were reported (Table 1). Differences in pregnancy outcomes were noted between retrospectively and prospectively reported pregnancies, with retrospective pregnancies resulting in substantially more miscarriages (Table 1). Retrospective reports can be biased toward the reporting of more unusual and severe outcomes, suggesting that it is important to characterize these pregnancies separately.

Prospective maternal pregnancy reports. Of the 226 prospective maternal CZP exposure pregnancies with available outcomes, $135(59.7 \%)$ arose from spontaneous reports and $23(10.2 \%)$ were reported for patients enrolled in CZP clinical trials. Most prospective pregnancy reports originated in North America (73.5\%) and were reported in women with CD (58.4\%; Table 1).

CZP exposure during pregnancy. Most pregnancies were exposed during the first trimester when the majority of fetal organ and organ system development takes place (Table 2). For the 132 pregnancies where trimester of exposure could be determined, 63 women stopped CZP in the first trimester (of which 34 had live births, 16 a miscarriage, and 13 an induced abortion); 48 continued CZP beyond the first trimester, and 16 started CZP in the second or third trimesters. Notably, 41 pregnancies were exposed to CZP in all 3 trimesters (Table 2).

Pregnancy and infant outcomes. Of the 226 pregnancies reported prospectively with available pregnancy outcomes, $182(80.5 \%)$ live births, 21 (9.3\%) miscarriages, and 22 $(9.7 \%)$ induced abortions were described; 1 pregnancy resulted in stillbirth. Cesarean deliveries were reported in

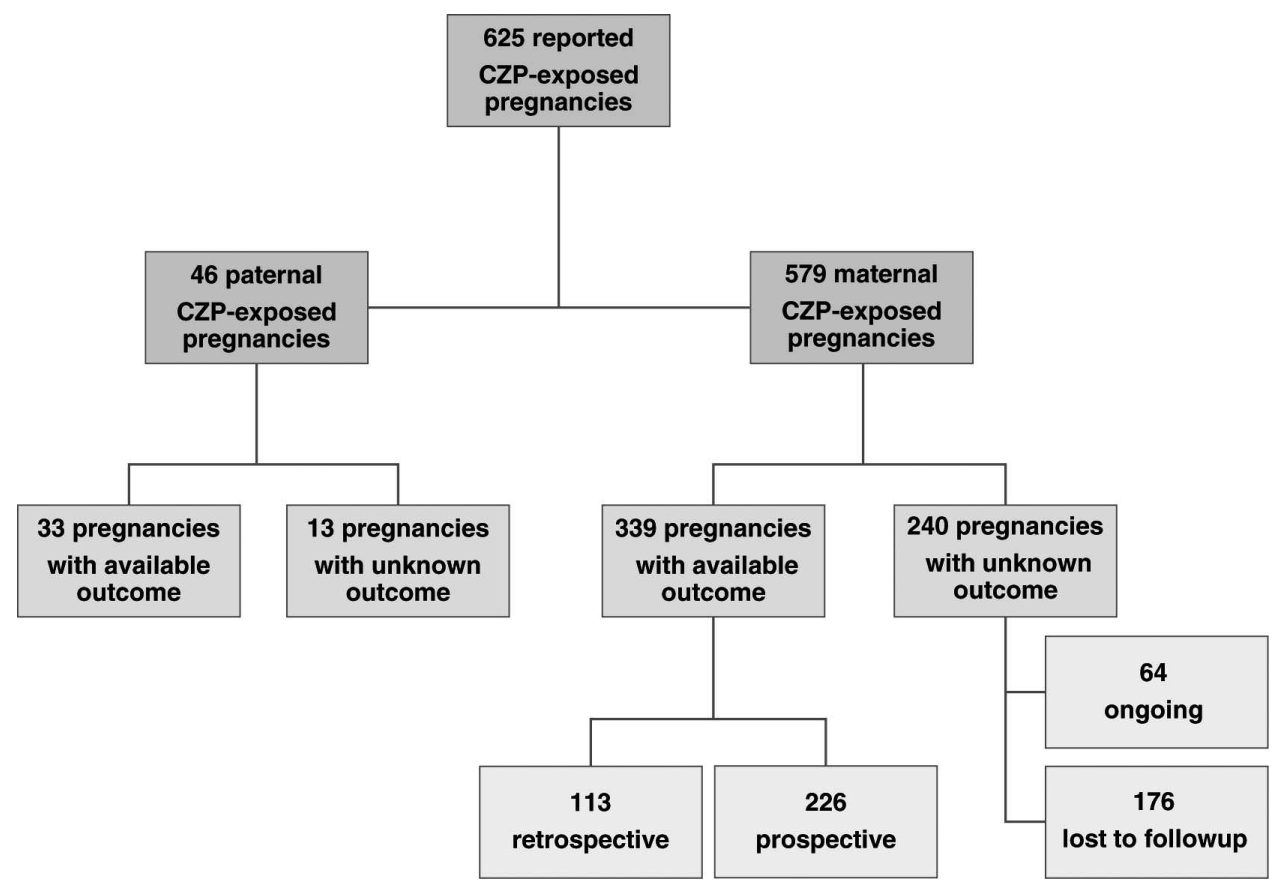

Figure 1. Distribution of pregnancy reports. CZP: certolizumab pegol. 
Table 1. Characteristics of maternal CZP-exposed pregnancies with known outcome by report type. Values are n (\%) unless otherwise specified.

\begin{tabular}{|c|c|c|c|}
\hline Characteristics & Prospective, $\mathrm{n}=226$ & Retrospective, $\mathrm{n}=113$ & Total, $\mathrm{n}=339$ \\
\hline \multicolumn{4}{|l|}{ Report source } \\
\hline Spontaneous & $135(59.7)$ & $82(72.6)$ & $217(64.0)$ \\
\hline Clinical trial & $23(10.2)$ & $8(7.1)$ & $31(9.1)$ \\
\hline Other clinical study* & $68(30.1)$ & $23(20.4)$ & $91(26.8)$ \\
\hline \multicolumn{4}{|l|}{ Region } \\
\hline North America & $166(73.5)$ & $78(69.0)$ & $244(72.0)$ \\
\hline Europe & $47(20.8)$ & $28(24.8)$ & $75(22.1)$ \\
\hline Asia & $7(3.1)$ & $2(1.8)$ & $9(2.7)$ \\
\hline Latin America & $3(1.3)$ & $3(2.7)$ & $6(1.8)$ \\
\hline Africa & $1(0.4)$ & $1(0.9)$ & $2(0.6)$ \\
\hline Oceania & $2(0.9)$ & $1(0.9)$ & $3(0.9)$ \\
\hline \multicolumn{4}{|l|}{ Indication } \\
\hline Rheumatic disease ${ }^{* *}$ & $78(34.5)$ & $40(35.4)$ & $118(34.8)$ \\
\hline Crohn disease & $132(58.4)$ & $60(53.1)$ & $192(56.6)$ \\
\hline Other & $16(7.1)$ & $13(11.5)$ & $29(8.6)$ \\
\hline \multicolumn{4}{|l|}{ Pregnancy outcome } \\
\hline Live birth & $182(80.5)$ & $72(63.7)$ & $254(74.9)$ \\
\hline Miscarriage & $21(9.3)$ & $31(27.4)$ & $52(15.3)$ \\
\hline Induced abortion & $22(9.7)$ & $10(8.8)$ & $32(9.4)$ \\
\hline Stillbirth & $1(0.4)$ & 0 & $1(0.3)$ \\
\hline \multicolumn{4}{|c|}{ Maternal age at EDD, yrs, mean (SD) } \\
\hline No. reported & 188 & 40 & 228 \\
\hline$<18$ & $1(0.5)$ & 0 & $1(0.4)$ \\
\hline $18-34$ & $137(72.9)$ & $23(57.5)$ & $160(70.2)$ \\
\hline$\geq 35$ & $50(26.6)$ & $17(42.5)$ & $67(29.4)$ \\
\hline \multicolumn{4}{|l|}{ Multiple gestation } \\
\hline Yes & $3(1.3)$ & $2(1.8)$ & $5(1.5)$ \\
\hline Live birth characteristics & Prospective, $\mathrm{n}=182$ & Retrospective, $\mathrm{n}=72$ & Total, $\mathrm{n}=254$ \\
\hline \multicolumn{4}{|c|}{ Gestational age at birth, weeks } \\
\hline No. reported & 133 & 28 & 161 \\
\hline$<32$, early preterm & $5(3.8)^{* * *}$ & 0 & $5(3.1)^{* * *}$ \\
\hline 32 to $<37$, preterm & $15(11.3)^{\dagger}$ & $7(25.0)$ & $22(13.7)^{\dagger}$ \\
\hline$\geq 37$, term & $113(85.0)$ & $21(75.0)$ & $134(83.2)$ \\
\hline \multicolumn{4}{|l|}{ Birth weight, g } \\
\hline No. reported & 120 & 24 & 144 \\
\hline$<1500$, very low & 0 & 0 & 0 \\
\hline $1500-2499$, low & $12(10.0)$ & $2(8.3)$ & $14(9.7)$ \\
\hline$\geq 2500$, normal & $108(90.0)$ & $22(91.7)$ & $130(90.3)$ \\
\hline Cesarean delivery & $63(34.6)^{\ddagger}$ & 17 (23.6) & $80(31.5)$ \\
\hline
\end{tabular}

* Other study includes noninterventional studies, healthy volunteer, open-label extensions, and compassionate use. ** Rheumatic disease includes rheumatoid arthritis, axial spondyloarthritis, psoriatic arthritis, and juvenile idiopathic arthritis. *** Includes 2 sets of twins. ${ }^{\dagger}$ Includes 1 set of twins. ${ }^{\ddagger}$ Includes all 3 sets of twins. CZP: certolizumab pegol; EDD: estimated delivery date.

$34.6 \%$ of the 182 pregnancies resulting in live births (Table 1). Among the 133 pregnancies with available gestational age at birth, $113(85.0 \%)$ were considered term ( $\geq 37$ weeks of gestation); 5 pregnancies were considered early preterm $(<$ 32 weeks of gestation), including 2 sets of twins; and 15 were preterm (between 32 and 37 weeks of gestation), including 1 set of twins. There were 3 sets of twins within the 182 live birth pregnancies, resulting in a total of 185 infants born (Table 1). Among the 120 live births with birth weight available, 90\% ( $\mathrm{n}=108)$ were of normal birth weight and
10\% had low birth weight (between 1500 and $2499 \mathrm{~g}$; Table 1). Birth weight was not available for any of the twin live births. There was 1 infant reported to be small for gestational age (data not shown).

There were some differences in pregnancy outcomes by report source: spontaneously reported pregnancy or pregnancies reported in women participating in other study types (e.g., NIS) were more likely to result in live births $(86.7 \%$ and $76.5 \%$, respectively) than pregnancies reported in clinical trial patients $(56.5 \%)$, which were more likely to

Personal non-commercial use only. The Journal of Rheumatology Copyright $\subset$ (2015. All rights reserved. 
Table 2. Characteristics of maternal CZP-exposed pregnancies with known outcome by pregnancy outcome. Values are n (\%) unless otherwise specified.

\begin{tabular}{|c|c|c|c|c|}
\hline Characteristics & Live Birth & Miscarriage & Induced Abortion & Stillbirth \\
\hline Prospective, $\mathrm{n}$ & 182 & 21 & 22 & 1 \\
\hline \multicolumn{5}{|l|}{ Report source } \\
\hline Clinical trial, $\mathrm{n}=23$ & $13(56.5)$ & $4(17.4)$ & $6(26.1)$ & 0 \\
\hline Other clinical study, $\mathrm{n}=68^{*}$ & $52(76.5)$ & $7(10.3)$ & $9(13.2)$ & 0 \\
\hline \multicolumn{5}{|l|}{ Indication } \\
\hline Rheumatic disease, $\mathrm{n}=78^{* *}$ & $57(73.1)$ & $9(11.5)$ & $11(14.1)$ & $1(1.3)$ \\
\hline \multicolumn{5}{|l|}{ Maternal age at EDD, yrs } \\
\hline No. reported & 155 & 19 & 13 & 1 \\
\hline$<18, \mathrm{n}=1$ & $1(100.0)$ & 0 & 0 & 0 \\
\hline $18-34, \mathrm{n}=137$ & $121(88.3)$ & $9(6.6)$ & $7(5.1)$ & 0 \\
\hline$\geq 35, \mathrm{n}=50$ & $33(66.0)$ & $10(20.0)$ & $6(12.0)$ & $1(2.0)$ \\
\hline \multicolumn{5}{|l|}{ Multiple gestation } \\
\hline $3, n=4$ & $4(100.0)$ & 0 & 0 & 0 \\
\hline Indeterminable, $\mathrm{n}=35^{\ddagger}$ & $31(88.6)$ & $2(5.7)$ & $2(5.7)$ & 0 \\
\hline \multicolumn{5}{|l|}{ Trimester(s) of CZP exposure } \\
\hline Preconception only, $\mathrm{n}=6^{\dagger}$ & $5(83.3)$ & 0 & $1(16.7)$ & 0 \\
\hline $1, \mathrm{n}=63$ & $34(54.0)$ & $16(25.4)$ & $13(20.6)$ & 0 \\
\hline $2, \mathrm{n}=1$ & $1(100.0)$ & 0 & 0 & 0 \\
\hline $3, n=3$ & $3(100.0)$ & 0 & 0 & 0 \\
\hline $1 \& 2, \mathrm{n}=7$ & $5(71.4)$ & $2(28.6)$ & 0 & 0 \\
\hline $2 \& 3, \mathrm{n}=12$ & $12(100.0)$ & 0 & 0 & 0 \\
\hline $1,2, \& 3, n=41$ & $41(100.0)$ & 0 & 0 & 0 \\
\hline Indeterminable, $\mathrm{n}=93^{\ddagger}$ & $81(87.1)$ & $3(3.2)$ & $8(8.6)$ & $1(1.1)$ \\
\hline Retrospective, $\mathrm{n}$ & 72 & 31 & 10 & 0 \\
\hline \multicolumn{5}{|l|}{ Report source } \\
\hline \multicolumn{5}{|l|}{ Indication } \\
\hline$<18, \mathrm{n}=0$ & 0 & 0 & 0 & 0 \\
\hline $18-34, n=23$ & $16(69.6)$ & $7(30.4)$ & 0 & 0 \\
\hline$\geq 35, n=17$ & $6(35.3)$ & $7(41.2)$ & $4(23.5)$ & 0 \\
\hline \multicolumn{5}{|l|}{ Multiple gestation } \\
\hline Yes, $\mathrm{n}=2$ & 0 & $2(100.0)$ & 0 & 0 \\
\hline \multicolumn{5}{|l|}{ Earliest trimester of CZP exposure } \\
\hline Preconception only, $\mathrm{n}=0^{\dagger}$ & 0 & 0 & 0 & 0 \\
\hline $1, \mathrm{n}=32$ & $14(43.8)$ & $14(43.8)$ & $4(12.5)$ & 0 \\
\hline $2, n=6$ & $6(100.0)$ & 0 & 0 & 0 \\
\hline $3, n=4$ & $4(100.0)$ & 0 & 0 & 0 \\
\hline Indeterminable, $\mathrm{n}=71^{\ddagger}$ & $48(67.6)$ & $17(23.9)$ & $6(8.5)$ & 0 \\
\hline \multicolumn{5}{|l|}{ Trimester(s) of CZP exposure } \\
\hline Preconception only, $\mathrm{n}=0^{\dagger}$ & 0 & 0 & 0 & 0 \\
\hline $1, \mathrm{n}=22$ & $4(18.2)$ & $14(63.6)$ & $4(18.2)$ & 0 \\
\hline $2, n=0$ & 0 & 0 & 0 & 0 \\
\hline $3, n=4$ & $4(100.0)$ & 0 & 0 & 0 \\
\hline $1 \& 2, n=2$ & $2(100.0)$ & 0 & 0 & 0 \\
\hline $2 \& 3, n=5$ & $5(100.0)$ & 0 & 0 & 0 \\
\hline $1,2, \& 3, n=6$ & $6(100.0)$ & 0 & 0 & 0 \\
\hline Indeterminable, $\mathrm{n}=74^{\ddagger}$ & $51(68.9)$ & $17(23.0)$ & $6(8.1)$ & 0 \\
\hline
\end{tabular}

* Other study includes noninterventional studies, healthy volunteer, open-label extensions, and compassionate use. ** Rheumatic disease includes rheumatoid arthritis, axial spondyloarthritis, psoriatic arthritis, and juvenile idiopathic arthritis. ${ }^{\dagger}$ Preconception only refers to cases where it is known that exposure stopped more than 14 and not more than 70 days prior to the first trimester. ${ }^{\ddagger}$ Cases where it was not possible to date CZP exposure and/or the pregnancy. CZP: certolizumab pegol; EDD: estimated delivery date. 
have an induced abortion $(26.1 \%)$ or miscarriage $(17.4 \%$; Table 2).

The majority of women $(72.9 \%)$ were between the ages of 18 and 34 years at EDD; 26.6\% of pregnancies occurred in women 35 and older (Table 1). Nineteen percent of prospective maternal pregnancies reported pregnancy complications, including preeclampsia/hypertension $(n=6)$, placental abnormalities $(n=4)$, infection $(n=5)$, disease flare $(n=10)$, and gestational diabetes $(n=5)$.

Congenital malformations. Eight cases of congenital malformation were reported in the 185 infants born, 3 delivered from mothers with RA and 5 delivered from mothers with CD (Table 3). One baby had 22q11.2 deletion syndrome, unilateral right kidney, hypospadias, and inguinal hernia. The remaining 7 babies were born with individual cases of anal fistula, left-sided vesico-ureteric reflux, pyloric stenosis, club foot, polydactyly (left hand, pinky side), renal cyst (no treatment required), and ankyloglossia.

The death of a single neonate from brain damage and pneumo-peritoneum (report originating in the United States) after maternal CZP exposure during pregnancy was reported. The neonatal death was 1 of female twins born at 25 weeks and 6 days gestation by preterm Caesarean section, which was performed because of sustained fetal bradycardia in both babies. The maternal information for this case was very limited: indication for CZP, timing of exposure in pregnancy, concomitant medications, and maternal age were not reported. Age of the neonate at death was not reported, and all attempts to followup with the reporting physician failed.

Disease activity in clinical trial pregnancy reports. Disease activity at the time of pregnancy detection was examined for subjects reporting pregnancy during clinical trials; information on disease activity was unavailable after the pregnancy was detected because pregnant patients were required to exit the clinical trials. CDAI and DAS28-ESR data for patients with $\mathrm{CD}$ and RA, respectively, at baseline visit prior to pregnancy report and change from baseline stratified by pregnancy outcome are presented in Table 4. CD subjects had moderate (median CDAI 288.8) to low (median CDAI 175.8) disease activity at study entry and at the visit prior to the pregnancy report, respectively, with lowest median CDAI observed in the subjects who reported miscarriages and highest median CDAI reported in subjects who had induced abortions (Table 4). RA disease activity (median DAS28-ESR 6.2) was high at baseline (study entry), whereas low disease activity was reported at the visit prior to the pregnancy report for subjects with pregnancies resulting in live births and DAS28-ESR remission or moderate disease activity for subjects whose pregnancies resulted in miscarriage and induced abortion, respectively (Table 4). It should be noted that because disease activity data were available only for a small number of pregnancy reports (12 CD and 14 RA), results are to be interpreted with caution.

For pregnancies in clinical trials, the concomitant medications around the time of pregnancy are presented in Table 5. Nonsteroidal antiinflammatory drugs and corticosteroids were the most frequent medications used. Five patients with a miscarriage used concomitant methotrexate (contraindicated in pregnancy, FDA category X).

Retrospective maternal pregnancy reports. Of the 113 pregnancies that arose from retrospective reports, $72(63.7 \%)$ live births, $31(27.4 \%)$ miscarriages, and 10 (8.8\%) induced abortions were reported (Table 1). No preconception CZP exposure was reported for the retrospective pregnancies; 22 pregnancies were exposed to CZP in the first trimester only, of which 14 resulted in miscarriage, 4 live births, and 4

Table 3. Description of congenital malformations.

\begin{tabular}{|c|c|c|c|c|}
\hline Abnormality & Report Type & Region & Study Type & $\begin{array}{l}\text { Indication } \\
\text { for CZP Use }\end{array}$ \\
\hline \multicolumn{5}{|l|}{ Left sided vesico-ureteric } \\
\hline Club foot & Prospective & North America & Noninterventional study & $\mathrm{CD}$ \\
\hline \multicolumn{5}{|c|}{$\begin{array}{l}\text { 22Q11.2 deletion syndrome, } \\
\text { unilateral right kidney, hypospadias, }\end{array}$} \\
\hline and inguinal hernia & Prospective & North America & Clinical trial & $\mathrm{CD}$ \\
\hline Pyloric stenosis & Prospective & North America & Clinical trial & $\mathrm{CD}$ \\
\hline Posterior ankyloglossia & Prospective & North America & Spontaneous & $\mathrm{CD}$ \\
\hline Polydactyl, left hand, pinky side & Prospective & North America & Spontaneous & RA \\
\hline Renal cyst, no treatment required & Prospective & North America & Clinical trial & RA \\
\hline Anal fistula & Prospective & Europe & Spontaneous & RA \\
\hline Cleft palate & Retrospective & North America & Spontaneous & $\mathrm{CD}$ \\
\hline Congenital diaphragmatic hernia & Retrospective & North America & Spontaneous & $\mathrm{CD}$ \\
\hline $\begin{array}{l}\text { Congenital morbus hirschsprung } \\
\text { and club feet }\end{array}$ & Retrospective & Europe & Spontaneous & RA \\
\hline $\begin{array}{l}\text { Right aortic arch with aberrant } \\
\text { left subclavian }\end{array}$ & Retrospective & Europe & Spontaneous & RA \\
\hline
\end{tabular}

CZP: certolizumab pegol; CD: Crohn disease; RA: rheumatoid arthritis. 
Table 4. Maternal disease activity by outcome for pregnancies from clinical trial reports: CD and RA subgroups*. Range of CDAI index: $0-600$, remission $<150$, low disease activity $150-219$, moderate disease activity $220-450$, and high disease activity $>450$. Range of DAS28-ESR index: $0-10$, remission $\leq 2.6$, low disease activity $>2.6$ to $\leq 3.2$, moderate disease activity $>3.2$ to $\leq 5.1$, and high disease activity $>5.1$.

\begin{tabular}{|c|c|c|c|c|}
\hline $\mathrm{CD}$ & $\begin{array}{l}\text { Live Birth, } \\
\quad \mathrm{n}=6\end{array}$ & $\begin{array}{c}\text { Miscarriage, } \\
n=2\end{array}$ & $\begin{array}{l}\text { Induced Abortion, } \\
\qquad \mathrm{n}=4\end{array}$ & $\begin{array}{l}\text { Total, } \\
\mathrm{n}=12\end{array}$ \\
\hline \multicolumn{5}{|c|}{ CDAI at baseline, CD study entry } \\
\hline Mean (SD) & $280.3(42.0)$ & $296.0(7.2)$ & $320.1(47.8)$ & $296.2(42.1)$ \\
\hline Median & 275.4 & 296.0 & 304.9 & 288.8 \\
\hline Min, $\max$ & 223,347 & 291,301 & 284,387 & 223,387 \\
\hline \multicolumn{5}{|c|}{ CDAI at visit prior to pregnancy report } \\
\hline Mean $(\mathrm{SD})$ & $180.5(100.9)$ & $151.4(2.3)$ & $168.8(99.3)$ & $171.7(86.2)$ \\
\hline Median & 200.3 & 151.4 & 163.2 & 175.8 \\
\hline Min, $\max$ & 34,304 & 150,153 & 72,277 & 34,304 \\
\hline \multicolumn{5}{|c|}{ CDAI change from baseline } \\
\hline Mean (SD) & $-99.9(74.1)$ & $-144.6(9.6)$ & $-151.3(84.7)$ & $-124.5(71.6)$ \\
\hline Median & -86.2 & -144.6 & -147.9 & -123.9 \\
\hline Min, $\max$ & $-189,1$ & $-151,-138$ & $-251,-58$ & $-251,1$ \\
\hline RA & $\begin{array}{l}\text { Live Birth, } \\
\quad \mathrm{n}=7\end{array}$ & $\begin{array}{c}\text { Miscarriage, } \\
n=4\end{array}$ & $\begin{array}{l}\text { Induced Abortion, } \\
\qquad \mathrm{n}=3\end{array}$ & $\begin{array}{l}\text { Total, } \\
\mathrm{n}=14\end{array}$ \\
\hline \multicolumn{5}{|c|}{ DAS28-ESR at baseline, RA study entry } \\
\hline Mean (SD) & $6.4(0.8)$ & $6.1(0.7)$ & $6.6(0.9)$ & $6.4(0.8)$ \\
\hline Median & 6.2 & 6.1 & 6.6 & 6.2 \\
\hline Min, $\max$ & $5.1,7.3$ & $5.4,7.0$ & $5.8,7.6$ & $5.1,7.6$ \\
\hline \multicolumn{5}{|c|}{ DAS28-ESR at visit prior to pregnancy report } \\
\hline Mean (SD) & $3.5(1.7)$ & $2.4(1.4)$ & $4.4(1.1)$ & $3.4(1.6)$ \\
\hline Median & 2.7 & 1.9 & 4.2 & 2.9 \\
\hline Min, $\max$ & $2.2,6.3$ & $1.3,4.5$ & $3.4,5.6$ & $1.3,6.3$ \\
\hline \multicolumn{5}{|c|}{ DAS28-ESR change from baseline } \\
\hline Mean (SD) & $-2.9(1.6)$ & $-3.7(1.6)$ & $-2.2(0.8)$ & $-3.0(1.5)$ \\
\hline Median & -3.0 & -4.0 & -2.1 & -3.0 \\
\hline Min, $\max$ & $-4.7,-0.6$ & $-5.2,-1.6$ & $-3.1,-1.6$ & $-5.2,-0.6$ \\
\hline
\end{tabular}

* Includes pregnancies collected between July 12, 2001 and March 28, 2013. CD: Crohn disease; RA: rheumatoid arthritis; CDAI: Crohn's Disease Activity Index; DAS28: 28-joint Disease Activity Score; ESR: erythrocyte sedimentation rate.

Table 5. Summary of concomitant medications taken at the time of pregnancy report. Values are $\mathrm{n}(\%)$.

\begin{tabular}{lccccc}
\hline Medication & $\begin{array}{c}\text { Live Birth, } \\
\mathrm{n}=39\end{array}$ & $\begin{array}{c}\text { Miscarriage, } \\
\mathrm{n}=10\end{array}$ & $\begin{array}{c}\text { Induced Abortion, } \\
\mathrm{n}=17\end{array}$ & $\begin{array}{c}\text { Unknown, } \\
\mathrm{n}=12\end{array}$ & $\begin{array}{c}\text { All, } \\
\mathrm{n}=78\end{array}$ \\
\hline Any & $37(94.9)$ & $10(100.0)$ & $17(100.0)$ & $10(83.3)$ & $74(94.9)$ \\
Methotrexate & $7(17.9)$ & $5(50.0)$ & $4(23.5)$ & $1(8.3)$ & $17(21.8)$ \\
Azathioprine & $7(17.9)$ & $2(20.0)$ & $1(5.9)$ & $1(8.3)$ & $11(14.1)$ \\
Mesalazine & $10(25.6)$ & $2(20.0)$ & $3(17.6)$ & 0 & $15(19.2)$ \\
NSAID & $13(33.3)$ & $4(40.0)$ & $8(47.1)$ & $3(25.0)$ & $28(35.9)$ \\
Steroids & $12(30.8)$ & $3(30.0)$ & $6(35.3)$ & $4(33.3)$ & $25(32.1)$ \\
Cyclosporine & 0 & 0 & $1(5.9)$ & 0 & $1(1.3)$ \\
Sulfasalazine & $3(7.7)$ & $1(10.0)$ & $2(11.8)$ & $2(16.7)$ & $8(10.3)$ \\
\hline
\end{tabular}

NSAID: nonsteroidal antiinflammatory drug.

women had induced abortions. Eight pregnancies continued CZP beyond the first trimester, and 9 pregnancies started CZP in the second and/or third trimesters; 6 pregnancies were exposed to CZP in all 3 trimesters (Table 2). There were 2 sets of twins, both resulting in miscarriage (Table 2). Four cases of congenital malformations were reported, 2 to mothers with RA and 2 to mothers with $\mathrm{CD}$. One baby had congenital morbus hirschsprung and club feet, 1 had cleft palate, 1 had a right aortic arch with aberrant left subclavian, and 1 had a congenital diaphragmatic hernia (Table 3). 
Paternal pregnancy reports. Among the 46 paternal-exposed pregnancies, outcomes were available for 33 pregnancies (Figure 1). Reports with unavailable or unknown pregnancy outcomes were more likely to be from NIS, have CD, and be reported in North America than those with outcomes available. The majority of paternal pregnancy reports originated in North America (65.2\%) and Europe (17.4\%; data not shown).

Of the 33 pregnancies following paternal exposure, 27 resulted in live birth, 4 miscarriage, 1 induced abortion, and 1 stillbirth.

\section{DISCUSSION}

To our knowledge, this is the largest cohort to date of pregnancies exposed to an anti-TNF medication. Most of the pregnancies had first-trimester CZP exposure, and up to a third of prospectively collected pregnancies continued drug use into the second and/or third trimesters. The large majority of prospectively collected pregnancies resulted in positive outcomes with low rates of miscarriage, preterm birth, and congenital anomalies. Prior reports of anti-TNF medications have not found increased rates of congenital malformations following exposure during pregnancy ${ }^{23,24,25,26,27}$, although data from large cohorts are not yet available ${ }^{7,8,9}$. Reports based on small numbers of pregnancies or case studies have suggested that the use of anti-TNF, such as adalimumab (ADA), infliximab (IFX), and etanercept, do not increase the risk of adverse pregnancy outcomes, and the data in our large single anti-TNF study confirms these reports ${ }^{24,28,29,30,31}$.

Published data from 31 patients with inflammatory bowel disease, 10 of whom received CZP during pregnancy, demonstrated low levels of CZP placental transfer to neonates (3.9\% of the plasma concentration measured in the mother) at birth $^{16}$. In comparison, concentrations of IFX and ADA were higher in cord blood at birth compared with maternal plasma concentrations (160\% and $153 \%$, respectively). IFX and ADA concentrations were higher in infants than mothers and were detectable for weeks to months after birth ${ }^{16}$. The neonatal FcRn is involved in the maternal-fetal transfer of antibodies ( $\gamma$ globulin, immunoglobulin $\mathrm{G}$ ), and the absence of the $\mathrm{Fc}$ portion in CZP likely interferes with binding to the $\mathrm{FcRn}$ and significantly reduces placental transfer ${ }^{32}$. Ex vivo placental transfer and animal model data also support low levels of CZP placental transfer ${ }^{17,33}$. Together, these results suggest that because of its unique lack of an Fc region, use of CZP during pregnancy may offer reduced exposure risk to the fetus after placental formation.

While our current study suggests that neonatal CZP exposure early in pregnancy is not associated with an increase in adverse pregnancy outcomes, there are important limitations to the analysis. For example, the drug safety database is designed as a surveillance reporting tool for adverse events, rather than an analysis tool; further, almost all reports within this database relate to patients receiving CZP therapy, and thus do not provide an untreated control group for compari- son. In addition, although our analysis includes a large number of pregnancy outcomes in patients receiving an anti-TNF, the numbers are still relatively small for less common events of interest, and information regarding disease activity and concomitant medications at conception/during pregnancy is limited. Similarly, because of the biased structure of the retrospective cohort, comparability of the frequency of congenital malformations reported in our study with that of the general population should be limited to the prospective cohort. Estimates of major birth defects are similar in the European Union $(2.6 \%)^{34}$ and the United States $(2.8 \%)^{35}$. Limited data availability because of the structure of the database and the reporting process also need to be considered; for example, regarding the timing of CZP exposure and concomitant medications taken during pregnancy.

An acknowledged limitation is also that the majority of the data originated from spontaneous postmarketing reports. While spontaneous reporting systems are recognized as essential elements for postmarketing pharmacovigilance surveillance, the data collected are affected by bias and often associated with inherent limitations, partly because of the passive and voluntary characteristic of the reporting systems. The differences in pregnancy outcomes between the prospective and retrospective pregnancy cohorts in our study highlight the difficulties of this reporting system. Limitations include recognized and extensive underreporting, variable quality and completeness of the data reported, and lack of information on drug exposure $36,37,38,39$. Incomplete reports were followed up repeatedly through written and telephone attempts for several months after expected delivery date. However, despite this, further data were unavailable for a proportion of pregnancy reports; this issue mostly affected spontaneous postmarketing reports. Incomplete reporting was a predominant limitation within our current study, and thus the results presented may not be representative of all CZP-exposed pregnancies.

Current data regarding CZP exposure before and during pregnancy are encouraging and suggest $\mathrm{CZP}$ exposure in utero, including first trimester exposure, does not adversely affect pregnancy outcomes. Our analysis represents a uniquely large number of pregnancies exposed to a single anti-TNF; further prospective data from increased numbers of pregnant women exposed to CZP will continue to be collected to comprehensively assess CZP safety and tolerability in pregnancy.

\section{ACKNOWLEDGMENT}

We thank the patients and investigators who were part of the studies included in this dataset. The authors acknowledge 'Matladi N. Ndlovu, PhD, UCB Pharma, Brussels, Belgium, for publication management; Kristel Luijtens, Daniela Negrini, and Maureen Cooney for statistical support; and Costello Medical Consulting for editorial and administrative support.

\section{REFERENCES}

1. Bush MC, Patel S, Lapinski RH, Stone JL. Perinatal outcomes in inflammatory bowel disease. J Matern Fetal Neonatal Med

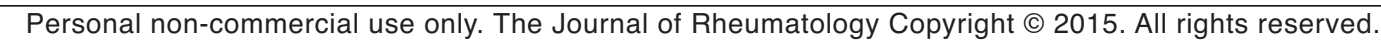


2004;15:237-41.

2. de Man YA, Hazes JM, van der Heide H, Willemsen SP, de Groot CJ, Steegers EA, et al. Association of higher rheumatoid arthritis disease activity during pregnancy with lower birth weight: results of a national prospective study. Arthritis Rheum 2009;60:3196-206.

3. Morales M, Berney T, Jenny A, Morel P, Extermann P. Crohn's disease as a risk factor for the outcome of pregnancy. Hepatogastroenterology 2000;47:1595-8.

4. Nørgård B, Hundborg HH, Jacobsen BA, Nielsen GL, Fonager K. Disease activity in pregnant women with Crohn's disease and birth outcomes: a regional Danish cohort study. Am J Gastroenterol 2007;102:1947-54.

5. Langen ES, Chakravarty EF, Liaquat M, El-Sayed YY, Druzin ML. High rate of preterm birth in pregnancies complicated by rheumatoid arthritis. Am J Perinatol 2014;31:9-14.

6. Østensen M, Förger F. Management of RA medications in pregnant patients. Nat Rev Rheumatol 2009;5:382-90.

7. Gisbert JP, Chaparro M. Safety of anti-TNF agents during pregnancy and breastfeeding in women with inflammatory bowel disease. Am J Gastroenterol 2013;108:1426-38.

8. Marchioni RM, Lichtenstein GR. Tumor necrosis factor- $\alpha$ inhibitor therapy and fetal risk: a systematic literature review. World J Gastroenterol 2013;19:2591-602.

9. Raja H, Matteson EL, Michet CJ, Smith JR, Pulido JS. Safety of tumor necrosis factor inhibitors during pregnancy and breastfeeding. Transl Vis Sci Technol 2012;1:6.

10. Mahadevan U, Cucchiara S, Hyams JS, Steinwurz F, Nuti F, Travis SP, et al. The London Position Statement of the World Congress of Gastroenterology on Biological Therapy for IBD with the European Crohn's and Colitis Organisation: pregnancy and pediatrics. Am J Gastroenterol 2011;106:214-23.

11. Ng SW, Mahadevan U. Management of inflammatory bowel disease in pregnancy. Expert Rev Clin Immunol 2013;9:161-73.

12. Østensen M, Förger F. How safe are anti-rheumatic drugs during pregnancy? Curr Opin Pharmacol 2013;13:470-5.

13. Mease PJ. Certolizumab pegol in the treatment of rheumatoid arthritis: a comprehensive review of its clinical efficacy and safety. Rheumatology 2011;50:261-70.

14. Simister NE, Story CM. Human placental Fc receptors and the transmission of antibodies from mother to fetus. J Reprod Immunol 1997;37:1-23.

15. Baker T, Kevorkian L, Nesbitt A. Investigation into the binding affinity of certolizumab pegol to FcRn and functional consequences for FcRn-mediated transcytosis: Comparison to infliximab, adalimumab and etanercept. Ann Rheum Dis 2013;72 Suppl 3:426.

16. Mahadevan U, Wolf DC, Dubinsky M, Cortot A, Lee SD, Siegel $\mathrm{CA}$, et al. Placental transfer of anti-tumor necrosis factor agents in pregnant patients with inflammatory bowel disease. Clin Gastroenterol Hepatol 2013;11:286-92.

17. Porter C, Kopotsha T, Smith B, Nesbitt A, Urbaniak S, Armstrong-Fisher S. No significant transfer of certolizumab pegol compared with IgG in the perfused human placenta in vitro. Ann Rheum Dis 2010;69 Suppl 3:210.

18. Brown D, Nesbitt A, Stephens S, Foulkes R. Lack of placental transfer and accumulation in milk of an anti-TNF PEGylated Fab' fragment in rats: P-0030. Inflamm Bowel Dis 2007;13:656.

19. CIMZIA (certolizumab pegol). Medication guide. [Internet. Accessed September 22, 2015.]. Available from: www.cimzia.com/assets/pdf/MedicationGuide.pdf

20. European Medicines Agency. CIMZIA (certolizumab pegol) EMA summary of product characteristics. [Internet. Accessed September 22, 2015.] Available from: www.ema.europa.eu/docs/en_GB/ document_library/EPAR_-_Product_Information/human/001037/ WC500069763.pdf

21. U.S. Department of Health and Human Services. Reviewer guidance: evaluating the risks of drug exposure in human pregnancies. [Internet. Accessed September 17, 2015.] Available from: www.fda.gov/downloads/Drugs//Guidances/ucm071645.pdf

22. National Institute of Health. Pregnancy: condition information. [Internet. Accessed September 22, 2015.] Available from: www.nichd.nih.gov/health/topics/pregnancy/conditioninfo/Pages/de fault.aspx

23. Ali YM, Kuriya B, Orozco C, Cush JJ, Keystone EC. Can tumor necrosis factor inhibitors be safely used in pregnancy? J Rheumatol 2010;37:9-17.

24. Mahadevan U, Martin CF, Sandler RS, Kane SV, Dubinsky M, Lewis JD, et al. PIANO: A 1000 patient prospective registry of pregnancy outcomes in women with IBD exposed to immunomodulators and biologic therapy. Gastroenterology 2012;142:S-149.

25. Roux CH, Brocq O, Breuil V, Albert C, Euller-Ziegler L. Pregnancy in rheumatology patients exposed to anti-tumour necrosis factor (TNF)-alpha therapy. Rheumatology 2007;46:695-8.

26. Verstappen SM, King Y, Watson KD, Symmons DP, Hyrich KL; BSRBR Control Centre Consortium, BSR Biologics Register. Anti-TNF therapies and pregnancy: outcome of 130 pregnancies in the British Society for Rheumatology Biologics Register. Ann Rheum Dis 2011;70:823-6.

27. Zelinkova Z, van der Ent C, Bruin KF, van Baalen O, Vermeulen HG, Smalbraak HJ, et al; Dutch Delta IBD Group. Effects of discontinuing anti-tumor necrosis factor therapy during pregnancy on the course of inflammatory bowel disease and neonatal exposure. Clin Gastroenterol Hepatol 2013;11:318-21.

28. Johnson DL, Luo Y, Jones KL, Chambers CD. Pregnancy outcomes in women exposed to adalimumab: an update on the Autoimmune Diseases In Pregnancy Project. Arthritis Rheum 2011;63 Suppl 10:1874.

29. Mahadevan U, Kane S, Sandborn WJ, Cohen RD, Hanson K, Terdiman JP, et al. Intentional infliximab use during pregnancy for induction or maintenance of remission in Crohn's disease. Aliment Pharmacol Ther 2005;21:733-8.

30. Scioscia C, Scioscia M, Anelli MG, Praino E, Bettocchi S, Lapadula $\mathrm{G}$. Intentional etanercept use during pregnancy for maintenance of remission in rheumatoid arthritis. Clin Exp Rheumatol 2011; 29:93-5.

31. Chambers CD, Johnson DL, Luo Y, Jimenez JL, Mirrasoul N, Salas E, et al. Pregnancy outcome in women treated with adalimumab for the treatment of rheumatoid arthritis: the OTIS autoimmune diseases in pregnancy project. Arthritis Rheum 2012;64 Suppl 10:2466.

32. Firan M, Bawdon R, Radu C, Ober RJ, Eaken D, Antohe F, et al. The MHC class I-related receptor, FcRn, plays an essential role in the maternofetal transfer of gamma-globulin in humans. Int Immunol 2001;13:993-1002.

33. Wakefield I, Stephens S, Foulkes R, Nesbitt A, Bourne T. The use of surrogate antibodies to evaluate the developmental and reproductive toxicity potential of an anti-TNFalpha PEGylated Fab' monoclonal antibody. Toxicol Sci 2011;122:170-6.

34. EUROmediCAT. European surveillance of congenital anomalies (EUROCAT). [Internet. Accessed September 17, 2015.] Available from: www.eurocat-network.eu/homepage

35. Centers for Disease Control and Prevention (CDC). Update on overall prevalence of major birth defects-Atlanta, Georgia, 1978-2005. MMWR Morb Mortal Wkly Rep 2008;57:1-5.

36. Ahmad SR. Adverse drug event monitoring at the Food and Drug Administration. J Gen Intern Med 2003;18:57-60.

37. Edwards IR. Spontaneous reporting - of what? Clinical concerns about drugs. Br J Clin Pharmacol 1999;48:138-41.

38. Fletcher AP. Spontaneous adverse drug reaction reporting vs event monitoring: a comparison. J R Soc Med 1991;84:341-4.

39. Palleria C, Leporini C, Chimirri S, Marrazzo G, Sacchetta S, Bruno $\mathrm{L}$, et al. Limitations and obstacles of the spontaneous adverse drugs reactions reporting: Two "challenging" case reports. J Pharmacol Pharmacother 2013;4 Suppl 1:S66-72. 